UNIVERSITE DE LAUSANNE - FACULTE DE BIOLOGIE ET DE MEDECINE

Division of Thoracic and Vascular Surgery

Centre Hospitalier Universitaire Vaudois, Lausanne, Switzerland

\title{
Tailored Thoracomyoplasty as a Valid Treatment Option for Chronic Post-Iobectomy Empyema
}

\author{
THESE \\ préparée sous la direction du Professeur Hans-Beat RIS MD \\ avec la co-direction du Docteur Michel GONZALES MD \\ et présentée à la Faculté de biologie et de médecine de \\ I'Université de Lausanne pour l'obtention du grade de
}

\section{DOCTEUR EN MEDECINE}

par

Ian FOURNIER

Médecin diplômé de la Confédération Suisse

Originaire de Nendaz (Valais)

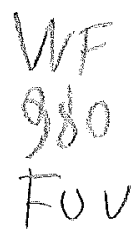

Lausanne

2012

$3 \operatorname{lit} 3658$

Bibliothèque Universitaire de Médecine / BiUM

CHUV-BHO8 - Bugnon 46

$\mathrm{CH}-1011$ Lausanne 
UNIL | Université de Lausanne

Faculté de biologie

Ecole Doctorale

et de médecine

Doctorat en médecine

\section{Imprimatur}

Vu le rapport présenté par le jury d'examen, composé de

Directeur de thèse Monsieurle Professeur Hans-Beat Ris

Co-Directeur de thèse

Expert

Monsieur le Docteur Gilbert Greub

Directrice de l'Ecole Madame le Professeur Stephanie Clarke doctorale

la Commission MD de l'Ecole doctorale autorise l'impression de la thèse de

\section{Monsieur Ian Fournier}

intitulée

Tailored Thoracomyoplasty as a Valid Treatment Option for Chronic Post-lobectomy Empyema

Lausanne, le 17 avril 2012

pour Le Doyen
de la Faculté de Biologie et de Médecine

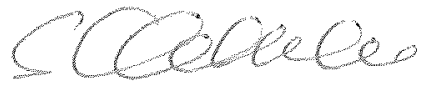

Madame le Professeur Stephanie Clarke Directrice de l'Ecole doctorale 


\section{Abstract}

Background: Chronic post-lobectomy empyema is rare but may require space obliteration for infection control. We report our experience by using a tailored thoracomyoplasty for this specific indication with respect to infection control and functional outcome.

Patients and Methods: We retrospectively analysed 17 patients ( 11 men, 6 women) with chronic post-lobectomy empyema and treated by thoracomyoplasty in our institution between 2000 and 2011 . All patients underwent an initial treatment attempt by use of chest tube drainage and antibiotics except those with suspicion of pleural aspergillosis $(n=6)$. In 5 patients, bronchus stump insufficiency was identified at preoperative bronchoscopy. A tailored thoracoplasty was combined with a serratus anterior - rhomboid myoplasty which also served to close a broncho-pleural fistula, if present. The first rib was resected in 11/17 patients.

Results: The 90-day mortality was $11.7 \%$. Thoracomyoplasty was successful in all surviving patients with respect to infection control, space obliteration and definitive closure of broncho-pleural fistula, irrespective of the type of infection, the presence of a broncho-pleural fistula and whether a $1^{\text {st }}$ rib resection was performed . Post-lobectomy pulmonary function testing before and after thoracoplasty revealed a mean predicted FEVI of $63.0 \pm 8.5 \%$ and $51.5 \pm 4.2 \%(\mathrm{p}=0.01)$, and a mean predicted DLCO of $59.8 \pm 11.6 \%$ and $54.5 \pm 12.5 \%$, respectively. Postoperative shoulder girdle dysfunction and scoliosis were prevented in patients willing to undergo intense physiotherapy.

Conclusions: Tailored thoracomyoplasty represents a valid option for patients with chronic post-lobectomy empyema without requiring a preceding open window thoracostomy. Space obliteration and infection control was equally obtained with and without first rib resection.

\section{Abstract word count: 250}


Tailored Thoracomyoplasty as a Valid Treatment Option for Chronic Post-lobectomy Empyema

Running title: Thoracomyoplasty for post-lobectomy empyema

Ian Fournier MD, Thorsten Krueger MD, Yabo Wang MD, Antoine Meyer MD, Hans-Beat Ris MD and Michel Gonzalez MD

Division of Thoracic and Vascular Surgery, Centre Hospitalier Universitaire Vaudois, Lausanne, Switzerland

Word count: 4054

Key words: Thoracoplasty - Empyema - Pleural space - Lobectomy - Broncho-pleural fistula

Corresponding Author: Michel Gonzalez MD, Division of Thoracic and Vascular Surgery, Centre Hospitalier Universitaire Vaudois, 1011 -Lausanne; Switzerland; phone: +41 7955638 20, fax: +41 2131423 58, email: michel.gonzalez@chuv.ch 


\section{Abstract}

Background: Chronic post-lobectomy empyema is rare but may require space obliteration for infection control. We report our experience by using a tailored thoracomyoplasty for this specific indication with respect to infection control and functional outcome.

Patients and Methods: We retrospectively analysed 17 patients ( 11 men, 6 women) with chronic post-lobectomy empyema and treated by thoracomyoplasty in our institution between 2000 and 2011. All patients underwent an initial treatment attempt by use of chest tube drainage and antibiotics except those with suspicion of pleural aspergillosis $(n=6)$. In 5 patients, bronchus stump insufficiency was identified at preoperative bronchoscopy. A tailored thoracoplasty was combined with a serratus anterior - rhomboid myoplasty which also served to close a broncho-pleural fistula, if present. The first rib was resected in $11 / 17$ patients.

Results: The 90-day mortality was $11.7 \%$. Thoracomyoplasty was successful in all surviving patients with respect to infection control, space obliteration and definitive closure of broncho-pleural fistula, irrespective of the type of infection, the presence of a broncho-pleural fistula and whether a $1^{\text {st }}$ rib resection was performed . Post-lobectomy pulmonary function testing before and after thoracoplasty revealed a mean predicted FEV1 of $63.0 \pm 8.5 \%$ and $51.5 \pm 4.2 \%(\mathrm{p}=0.01)$, and a mean predicted DLCO of $59.8 \pm 11.6 \%$ and $54.5 \pm 12.5 \%$, respectively. Postoperative shoulder girdle dysfunction and scoliosis were prevented in patients willing to undergo intense physiotherapy.

Conclusions: Tailored thoracomyoplasty represents a valid option for patients with chronic post-lobectomy empyema without requiring a preceding open window thoracostomy. Space obliteration and infection control was equally obtained with and without first rib resection.

\section{Abstract word count: $\mathbf{2 5 0}$}




\section{Introduction}

The incidence of a residual pleural space after lobectomy ranges from 5-21\% at discharge after removal of the chest tubes [1-4]. In more than $95 \%$ of the patients, it resolves without further treatment during follow up; complete regression was observed in $91 \%$ of patients within one year after operation [3]. However, in $2 \%$ of the patients, infection will subsequently develop within a residual post-lobectomy space $[1-3,5]$. Prolonged air leak ( $>7$ days) and chest tube drainage, bronchus stump insufficiency with broncho-pleural fistula, age, previous chemotherapy or irradiation and associated co-morbidity are all implicated in the development of a postlobectomy empyema which is mainly observed after upper lobectomy [3]. Prolonged air leak and chest tube drainage are present in $10 \%$ of patients after lobectomy and are the main causes of contamination and infection of a residual pleural space after lung resection whereas bronchus stump insufficiency and broncho-pleural fistula are relatively rare after lobectomy. In the presence of a broncho-pleural fistula, the infected pleural space will continuously contaminate the remaining lung leading to repeated pneumonia and destruction of the remnant lung. Microbiological assessment of chronically infected post-lobectomy spaces usually reveals polymicrobial or fungal colonialization [6].

The management of infected post-resectional residual spaces after lobectomy remains challenging $[6,7]$. As for parapneumonic empyema, the goal of treatment relies in the re-expansion of the remnant lung leading to the obliteration of the infected space [8,9]. This may be obtained by antibiotics, CT-guided pigtail drainage and fibrinolytic instillation in the early phase of infection. However, in case of chronic infections, the lung is trapped as seen in chronic empyema. In this situation, open decortication is less likely to be successful compared to parapneumonic empyema since the trapped remaining lung might fail to fill the chest cavity, even after decortication. This holds especially true in the presence of a broncho-pleural fistula or the colonization of the residual cavity by multi-resistant germs or Aspergillus fumigatus where complete space obliteration is of paramount importance to achieve permanent control of infection. In case of a chronic post-resection empyema open window thoracostomy [10] may therefore be required with packing of the cavity or treatment by vacuum assisted wound management ${ }^{11}$ followed by space obliteration either by intrathoracic omentum [12] of muscle transfer [13-15] or tailored thoracoplasty [16-20] or a combination of both (thoracomyoplasty) [21,22]. Although there is some recrudescence in the recent literature for thoracomyoplasty and its role in the modern thoracic surgery armamentarium, very few reports focus on its specific use for the treatment of chronically infected pleural spaces after lobectomy which are increasingly observed in our days in the context of neoadjuvant or 
adjuvant radio-chemotherapy applied for locally advanced NSCLC, or after lobectomy performed in immunodeficient patients. This report analyses a one decade single institution experience using thoracomyoplasty for the treatment of post-lobectomy empyema with respect to postoperative mortality, morbidity, control of infection and functional outcome, including pulmonary function testing, scoliosis and shoulder girdle mobility. 


\section{Material and Methods}

We retrospectively reviewed all patients undergoing thoracomyoplasty for a chronically infected pleural space after lobectomy in our institution between 2000 and 2010. The study was reviewed and approved by the Institutional Ethical Committee and individual patient consent was waived.

Clinical work-up: All patients underwent clinical, cardiopulmonary, nutritional and radiological work up prior to operation. CT-guided pigtail drainage followed by microbiological analysis was performed in all patients without suspicion of aspergillosis as well as bronchoscopy in order to assess the presence or absence of a bronchus stump insufficiency or a broncho-pleural fistula. Aspergillosis was suspected on the base of typical signs on CT imaging (fungus ball) or in the presence of Aspergillus precipitin. Thoracomyoplasty was then performed without an attempt of drainage. Thoracomyoplasty was performed if a chronically infected residual pleural space failed to resolve with a one week regimen of antibiotics, pigtail drainage and fibrinolytic instillation. This time frame was also used to assess cardiopulmonary reserves and to optimize the nutritional status. An open window thoracostomy preceding the thoracomyoplasty was not performed in any patient.

Technique of limited thoracomyoplasty: Epidural thoracic anesthesia was installed prior to general anesthesia and endotracheal intubation. The incision was performed at the level of the initial posterolateral incision and prolonged cranially if necessary. The latissimus dorsi muscle was divided at its initial site of division and the serratus anterior and the rhomboid muscles were preserved, including their chest wall insertion. The ribs I-VII were exposed. An extramusculoperiosteal tailored thoracoplasty was performed as described by Alexander. The extent of rib resection was determined by the extent of the residual cavity and included one rib below the most inferior part of disease. A sloping resection of the anterior part of the ribs was performed with progressively less resection for more caudal located ribs. Posteriorly, the ribs were disarticulated at the level of the costotransversal and costo-vertebral ligament but the transverse processes were preserved. The $1^{\text {st }}$ rib was resected in 11/17 patients but an extrafacial apicolysis was routinely performed.

The residual cavity was accessed between two intercostals muscles and was debrided by dissecting the inflammatory peel overlying the lung but only at the level of the infected pleural space. The same procedure was applied for all types of infection including Aspergillus fumigatus colonialization (Figure 1). 
The serratus anterior and the rhomboideus muscles were detached en bloc from their insertion on the undersurface of the scapula while keeping their chest wall insertion intact (Figure 2). This allowed the coverage of the underlying lung and intercostal muscle layer by an additional well-vascularized muscle layer. A bronchopleural fistula, if present, was closed by suturing the serratus muscle into the debrided bronchial stump by use of interrupted 4-0 Prolene ${ }^{(B)}$ stitches as previously described without attempting a primary bronchus stump closure $[23,24]$. The tip of the scapula was resected in order to avoid impingement with the remaining ribs. One chest tube was inserted between the scapula and the muscle layers. The soft-tissue closure was performed in two layers (latissimus dorsi and skin). The chest tubes were removed in the absence of air leaks and excessive of liquid drainage $(<150 \mathrm{ml} / 24 \mathrm{~h}$ ) (Figure 3). Early postoperative physiotherapy-assisted shoulder girdle mobilization was prescribed to prevent a frozen shoulder. In patients with pleural or invasive aspergillosis, Voriconazole (Vfend ${ }^{(B)}$ was prescribed for a period of 3 months.

Follow-up: The postoperative course was evaluated with respect to 90-day mortality, morbidity, wound healing, control of infection and space obliteration and hospital stay. After discharge, all surviving patients were regularly followed in the outpatient clinic on a clinical and radiological base with respect to pain control, wound healing, shoulder girdle function and control of infection. Pulmonary function testing was performed 3 months after the operation. The student's t-test for paired observation was used for statistical analysis where appropriate and significance was accepted at $p<0.05$ using a bidirectional hypothesis. 


\section{Results}

Seventeen patients underwent tailored thoracomyoplasty for chronically infected residual pleural spaces after lobectomy between 2000 and 2010 at our institution. There were 11 men and 6 women with a mean age of 63 (range 40-77) years. All patients presented with additional comorbidity including coronary artery disease $(n=5)$, chronic renal failure $(n=3)$, stage IV COPD $(n=5)$, diabetes $(n=2)$ and steroid medication $(n=2)$. The indication for lobectomy was non-small cell lung cancer $(n=9)$, lung abscess $(n=4)$, bronchiectasis $(n=2)$, heterogeneous emphysema with upper lobe predominance $(n=1)$ and aspergilloma in a sarcoidosis-induced lung excavation $(n=1)$. The intervention was right- and left sided in 10 and 7 patients, respectively. Six patients with stage III NSCLC received neoadjuvant radio-chemotherapy and 3 with stage II NSCL had adjuvant chemotherapy. All patients underwent initial lobectomy by a posterolateral thoracotomy with division of the latissimus dorsi but preservation of the serratus anterior muscle.

The time interval between lobectomy and clinical appearance of residual pleural space infection ranged from 28 days to 4 years (median 40 days). Eleven patients (65\%) presented with infection within 3 months after lobectomy. The microbiological analysis of the infected pleural space revealed methicillin-resistant Staphylococcus aureus $(\mathrm{n}=3)$, Steptococcus pneumonia $(\mathrm{n}=2)$, Enterococcus $(\mathrm{n}=1)$, Pseudomonas $(\mathrm{n}=1)$ and polymicrobial infection $(n=1)$. No germs were identified in two patients. Seven patients presented colonialisation of the pleural space by Aspergillus fumigatus (table 1) and three of these patients had radiological signs of chronic radiation pneumonitis. Broncho-pleural fistulas were diagnoses in five patients by pre-operative bronchoscopy.

Thoracomyoplasty was performed as a one stage procedure in all patients and a median of five (range 4 to 8 ) ribs were removed. The first rib was resected in 11 patients (65\%). All patients underwent serratus-rhomboideus muscle transposition which was used to close a broncho-pleural fistula in five patients.

The 90 -days postoperative mortality $(2 / 17)$ was $11.7 \%$. One patient died 10 days postoperatively of anoxic brain damage which occurred in the context of massive aspergillosis-related haemoptysis requiring cardiopulmonary reanimation and unsuccessful embolisation three days before thoracoplasty. However, there was no recurrence of hemoptysis in the postoperative phase in this patient. Another patient died 40 days postoperatively from contralateral pneumonia and rapidly progressing malignant disease. In both patients, a decline of aggressive treatment and installation of TLC was realized due in the context of an incurable situation. 
The postoperative morbidity $(9 / 17)$ was $52 \%$. Two patients required a re-intervention in the early postoperative phase, one for bleeding and one for closure of a persistent broncho-pleural fistula with by the debrided bronchial muscle layer. Nine patients developed a postoperative pneumonia, 2 of them required non-invasive ventilation and 2 a temporary tracheostomy mainly related to preoperative compromised pulmonary functions. One patient developed in addition a Clostridum difficile colitis. The median ICU and hospital stay were 2 (range $0-33$ ) days and 23 (range 11-90) days, respectively.

Control of pleural space infection: Follow-up was obtained in all surviving 15 patients with a mean follow up time of 15 (range 3-100) months. Seven patients died of progressive tumor disease within the first two years and one patient of AIDS 5 years after thoracoplasty. Thoracomyoplasty was successful in all patients with respect to infection control, space obliteration and definitive closure of broncho-pleural fistula, irrespective of whether the ${ }^{\text {st }}$ rib was removed or not. Referring to their operation, all but one patients claimed to experience a life without restriction in their daily activities during follow-up.

Shoulder girdle function and cervical scoliosis: Prolonged (> 3 months) opioid-based analgesic medication and intense physiotherapy-assisted shoulder girdle mobilization was required in all patient to prevent a frozen shoulder. After 3 months, abduction of the involved arm ranged between $170^{\circ}$ and $80^{\circ}$ (Figure 4 ). The same holds true for patients with $1^{\text {st }}$ rib resection. Despite intense physiotherapy, scoliosis of $30^{\circ}$ towards the operated side was observed in the majority of patients with $1^{\text {st }}$ rib resection. In contrast, scoliosis deformities were not observed in patients without $1^{\text {st }}$ rib resection. In general, daily activity and quality of life was substantially impaired by thoracoplasty.

Pulmonary function testing: In 7 patients, post-lobectomy pulmonary function testing was available before and after thoracomyoplasty. Pulmonary function testing before and after thoracoplasty revealed a mean predicted FEV 1 of $63.0 \pm 8.5 \%$ and $51.5 \pm 4.2 \%$ and a mean predicted DLCO of $59.8 \pm 11.6 \%$ and $54.5 \pm 12.5 \%$, respectively. The difference was statistically significant for FEV1 $(p=0.01)$ but not for DLCO. 


\section{Discussion}

Thoracoplasty in combination with muscle flap transposition has been applied successfully to achieve pleural space obliteration in patients presenting chronic post-lobectomy empyema [10,17-22]. This complex pathological entity is increasingly observed in the context of pulmonary resections performed after radiochemotherapy or resections realized in immune-deficient patients. In these situations, the pleural space usually contains polymicrobial infections including multi-resistant germs or aspergillus fumigatus [16,18,19] which requires efficient space obliteration with healthy vascularized tissues in order to obtain permanent infection control.

In our series, we reported on 17 patients with chronically infected pleural spaces after lobectomy treated by thoracomyoplasty over the last decade. All of them had additional and multiple co-morbidities such as coronary artery disease, chronic renal failure, advanced COPD, diabetes or steroid medication which might have contributed to impaired immunity. This may in part explain the rather high 90-day postoperative mortality and morbidity in our series. Indeed, the two postoperative deaths in our series were merely related to progressive decline of treatment delivery due to an incurable underlying process (anoxic brain damage after previously performed unsuccessful embolisation for massive hemotpysis; tumor progression) than to the procedure itself. Conversely, thoracomyoplasty was successful in all surviving patients with respect to infection control, space obliteration and definitive closure of broncho-pleural fistulas.

The majority of patients underwent lobectomy for lung cancer with either neoadjuvant or adjuvant radio-chemotherapy, three with radiological signs of chronic radiation pneumonitis. In the majority of patients, the infected pleural space revealed multi-resistant germs or aspergillus fumigatus and $30 \%$ of the patients presented with a broncho-pleural fistula. All patients were treated by a one-stage tailored Alexander thoracoplasty with extrafascial apicolysis; however, first rib resection was progressively abandoned over time to decrease the risk of cervical scoliosis development. In addition to tailored thoracoplasty, the patients underwent a modified serratus anterior-rhomboideus muscle flap transposition for additional space obliteration. This maneuver allowed efficient space obliteration and the simultaneous closure of a broncho-pleural fistula if present as a one-stage procedure which rendered the realization of a preceding thoracic window unnecessary. A temporary thoracic window is usually performed in the initial phase of treatment for control of pleural infection followed by space obliteration by thoracoplasty or muscle flaps in a second step $[2,9,21]$. Here we describe a modified technique of myoplasty which consists of detaching the serratus anterior and rhomboideus muscle 
layers en bloc from the scapula without disinsertion of the muscles from the chest wall. This allowed for the coverage of the entire underlying lung and efficient obliteration of the residual cavity but required the resection of the tip of the scapula in order to avoid impingement of the scapula at the level of the remaining ribs. In case of broncho-pleural fistula, the debrided bronchial stump was closed by suturing the muscle directly into the defect without attempting a primary bronchial stump repair [23.24]. The advantages of transposed serratus anteriorrhomboideus muscle flaps over other vascularized tissues such as omentum [12] or pectoralis mayor muscles [25] are their large size, their mechanical strength and their proximity of the usually apically localized residual spaces [14] which renders them easily accessible through the same incision used to perform thoracoplasty. Others authors have described omentum [12] or pectoralis major flaps [25] for space obliteration but these techniques require additional dissections on remote sites and were judged unnecessary in the presence of serratus anterior-rhomboideus flaps which efficiently obliterated the residual spaces after lobectomy in our patients.

Two recent studies assessed thoracoplasty in the context of post-lobectomy empyema. Stefani et al [20] reported on 19 patients who underwent an open window thoracostomy and thoracoplasty was only considered in those eight patients where thoracic window failed. Permanent infection control was obtained in $6 / 8$ patients (75\%) after thoracoplasty. Krassas et al [22] reported on 8 patients who underwent apical thoracoplasty for postlobectomy empyema. Aspergillus fumigatus was present in 6 patients; three of these patients (50\%) revealed radiation pneumonitis in their remaining lung. All 8 patients had permanent control of infection in the obliterated pleural cavity. In both series, the authors observed a progressively increased association of extrathoracic muscle flap transposition to thoracoplasty over time in patients with broncho-pleural fistulas, large spaces or insufficient collapse after thoracoplasty alone [20,22].

Regarding the functional aspects of thoracomyoplasty in our series, tailored thoracoplasty combined with serratus anterior-rhomboideus myoplasty resulted in a significant loss of FEV1 ( $\triangle 12 \%$ predicted) but not of DLCO. Postoperative shoulder girdle function could be restored but required intensive and long-lasting physiotherapy-assisted shoulder girdle mobilization. Recently, Botianu et al. reported on 76 patients who underwent thoracoplasty in association with muscular flap transposition for chronic intrathoracic infections of various etiologies [13]. Impaired shoulder function was observed in $5 / 76$ patients $(6.6 \%)$ during follow-up and pulmonary functions were not significantly different before and after thoracoplasty. A concern remains the cosmetical aspects of thoracoplasty which were in general reasonably well accepted, probably due to the limited number of ribs resected. This observation was also confirmed by others authors $[18,20]$. 
In conclusion, one-stage tailored thoracoplasty associated with serratus anterior-rhomboideus myoplasty is a useful technique of last resort for patients with chronically infected residual spaces after lobectomy. It affords optimal space obliteration and control of infection even in the presence of a broncho-pleural fistula without the need of open window thoracostomy or first rib resection. 
Table 1. Patient's characteristics of one-stage tailored thoracomyoplasty for chronically infected residual pleural spaces after lobectomy

\begin{tabular}{|c|c|c|c|c|c|c|}
\hline Sex & Age & Cause of lobectomy & Pleural microbiology & $\begin{array}{l}\text { Time interval }{ }^{1} \\
\text { (days) }\end{array}$ & $\begin{array}{l}\text { Resected ribs } \\
\text { (number) }\end{array}$ & $\begin{array}{l}\operatorname{LOS}^{2} \\
\text { (days) }\end{array}$ \\
\hline M & 64 & Abscess LUL ${ }^{3}$ & Aspergillus & 360 & $1-V$ & 15 \\
\hline$M$ & 46 & Abscess LUL & polymicrobial & 30 & II-VI & 25 \\
\hline M & 61 & NSCLC LUL & negative & 60 & II-IV & 11 \\
\hline M & 63 & NSCLC RUL & negative & 28 & $\mathrm{II}-\mathrm{V}$ & 24 \\
\hline M & 69 & LVRS $^{4}$ RUL & Streptococcus & 30 & I-IV & 20 \\
\hline M & 68 & NSCLC LUL & Staphylococcus MRSA & 90 & I-IV & 18 \\
\hline $\mathrm{F}$ & 76 & NSCLC LUL & Streptococcus & 40 & I-IV & 35 \\
\hline M & 51 & Bronchiectasis LUL & Staphylococcus MRSA & 30 & I-IV & 23 \\
\hline M & 40 & Sarcoidosis LUL & Aspergillus & 40 & I-VII & 14 \\
\hline M & 69 & NSCLC RUL & Enterococcus & 30 & $\mathrm{I}-\mathrm{V}$ & 45 \\
\hline M & 77 & Bronchiectasis RUL & Aspergillus & 28 & $\mathrm{I}-\mathrm{VI}$ & 60 \\
\hline $\mathrm{F}$ & 53 & Bronchiectasis LUL & Aspergillus & 1440 & $\mathrm{I}-\mathrm{VI}$ & 14 \\
\hline $\mathrm{F}$ & 69 & Abscess LUL & Aspergillus & 1445 & I-VI & 50 \\
\hline M & 74 & NSCLC RUL & Staphylococcus MRSA & 46 & $I-V$ & 90 \\
\hline M & 61 & NSCLC RUL & Pseudomonas & 1080 & II-VI & 18 \\
\hline $\mathrm{F}$ & 67 & NSCLC RUL+ML & Aspergillus & 1448 & II-VI & 25 \\
\hline $\mathrm{F}$ & 59 & NSCLC RUL+ML & Aspergillus & 730 & II-IV & 21 \\
\hline
\end{tabular}

\footnotetext{
1 Time interval between lobectomy and clinical appearance of empyema

${ }^{2}$ Length of hospitalization after thoracomyoplasty

${ }^{3}$ LUL: left upper lobe, RUL: right upper lobe, ML: middle lobe

${ }^{4}$ Lung volume reduction surgery
} 


\section{Legend}

Figure 1: a) Chest $\mathrm{CT}$ scan showing an apical residual space after lobectomy with suspicion of pleural aspergillosis; b), intraoperative view confirming the presence of Aspergillus fumigatus.

Figure 2: Schematic drawing showing $a$ ), the extent of tailored thoracoplasty and $b$ ), the modified serratus anterior (SA) - rhomboideus (RHO) myoplasty with detachment of both muscles from the scapula while leaving their chest wall insertion intact. The tip of the scapula is resected in order to prevent impingement of the scapula with the remaining ribs.

Figure 3: a) preoperative chest radiography of a chronically infected residual space which failed to respond to chest tube drainage and antibiotics; b) postoperative radiography after limited thoracomyoplasty.

Figure 4: Shoulder girdle mobility with posterior and anterior view, one year after a tailored thoracomyoplasty and resection of the tip of the scapula. 


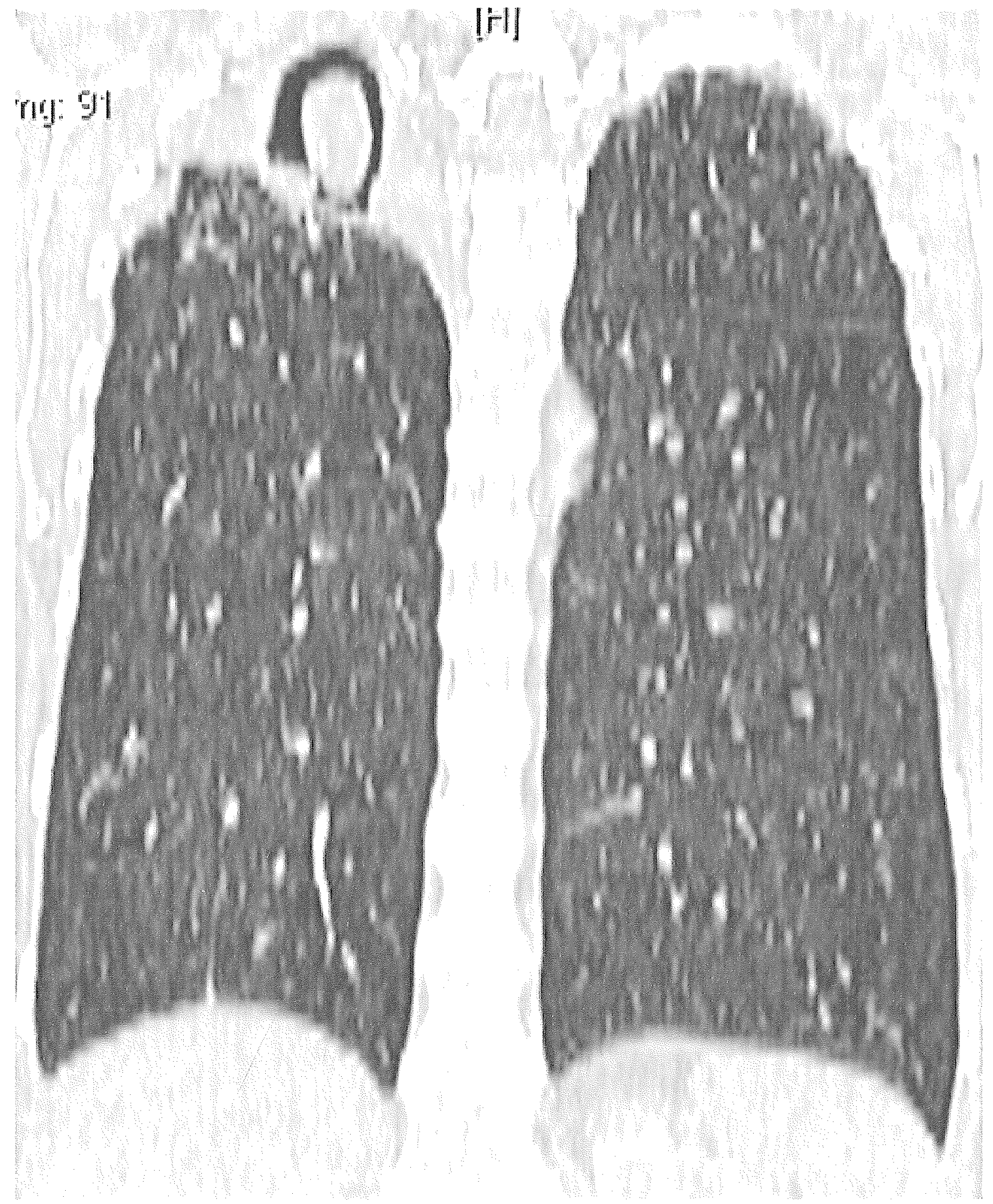

figure la) 


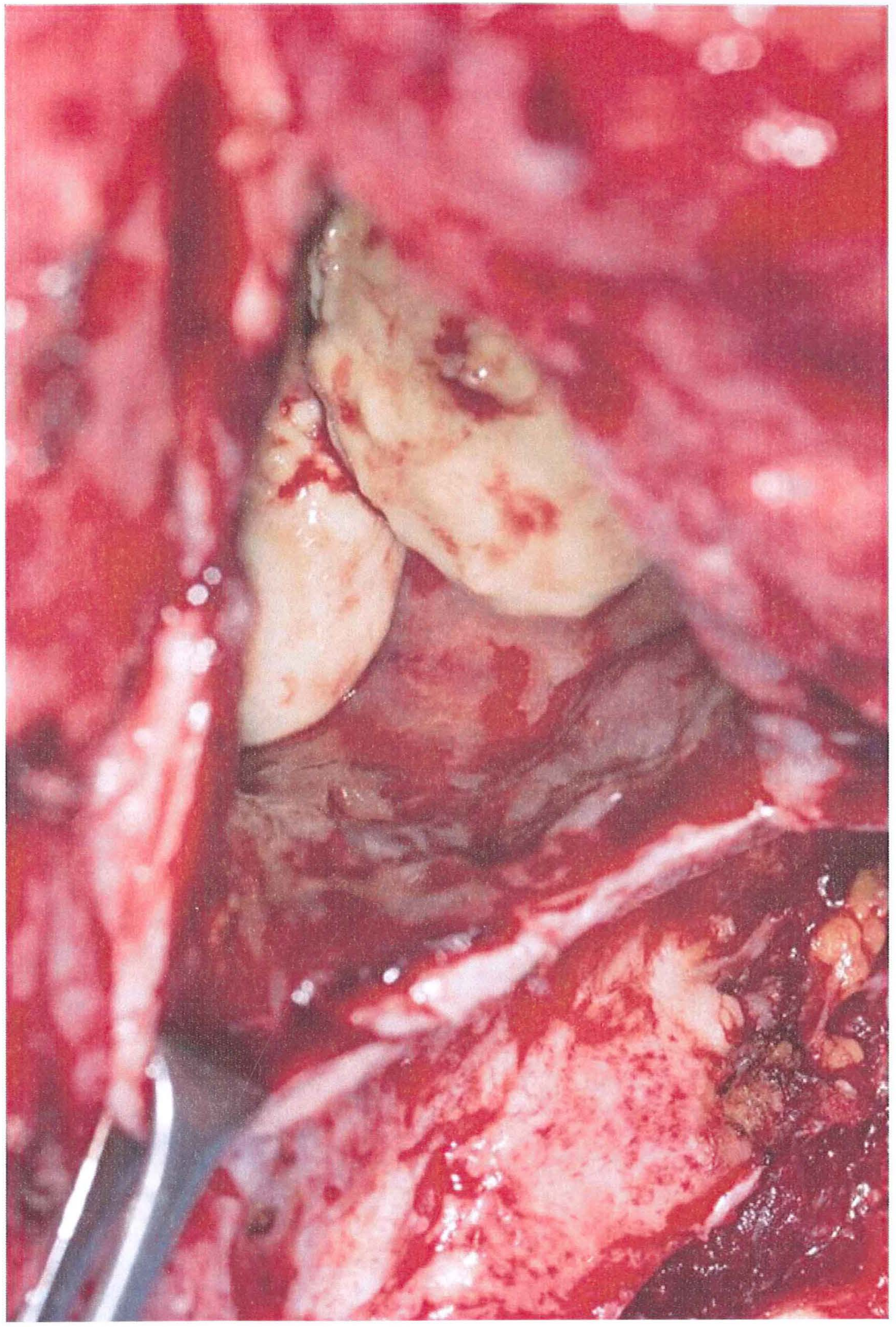

figure $1 b$ ) 


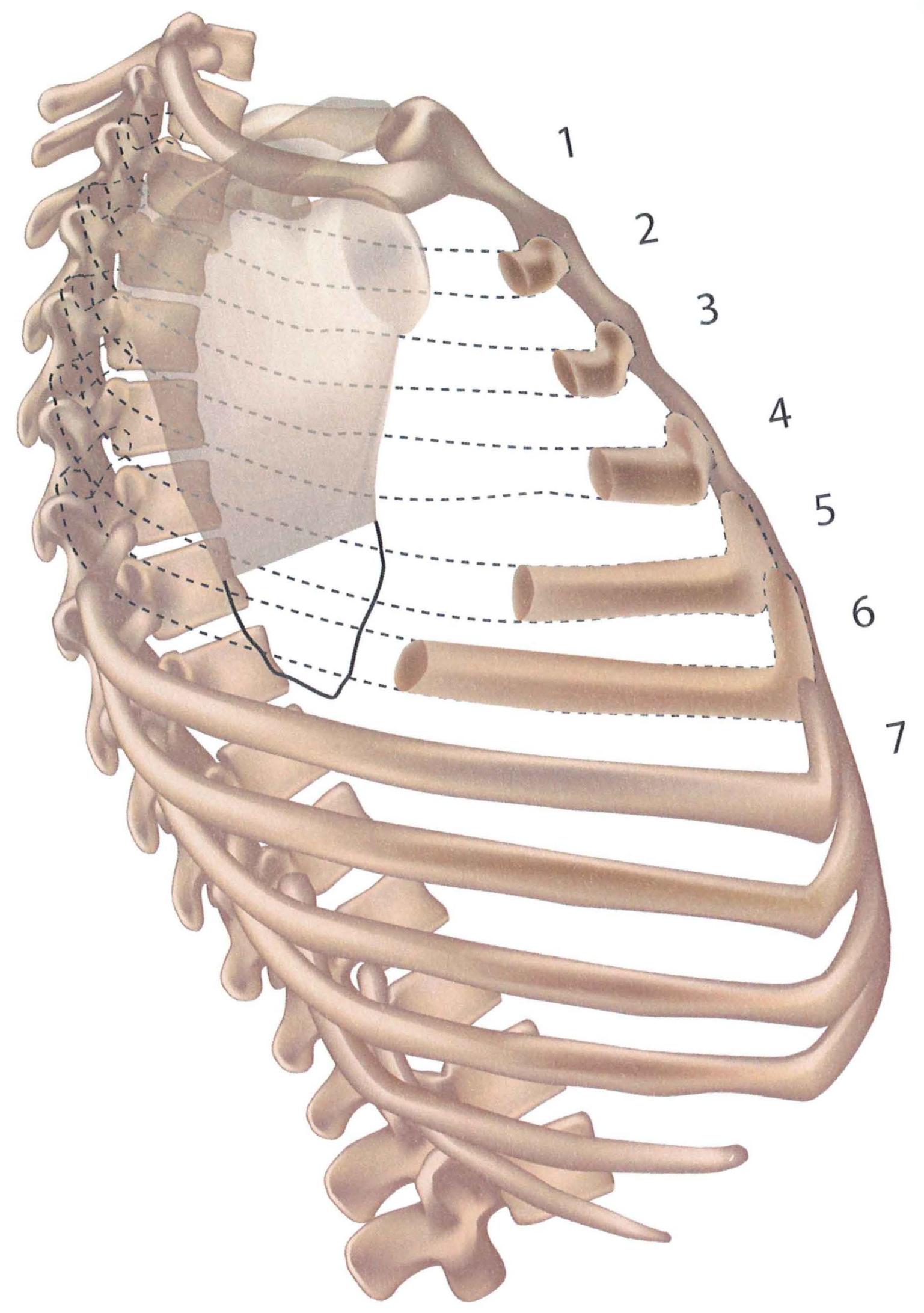

figure2a) 


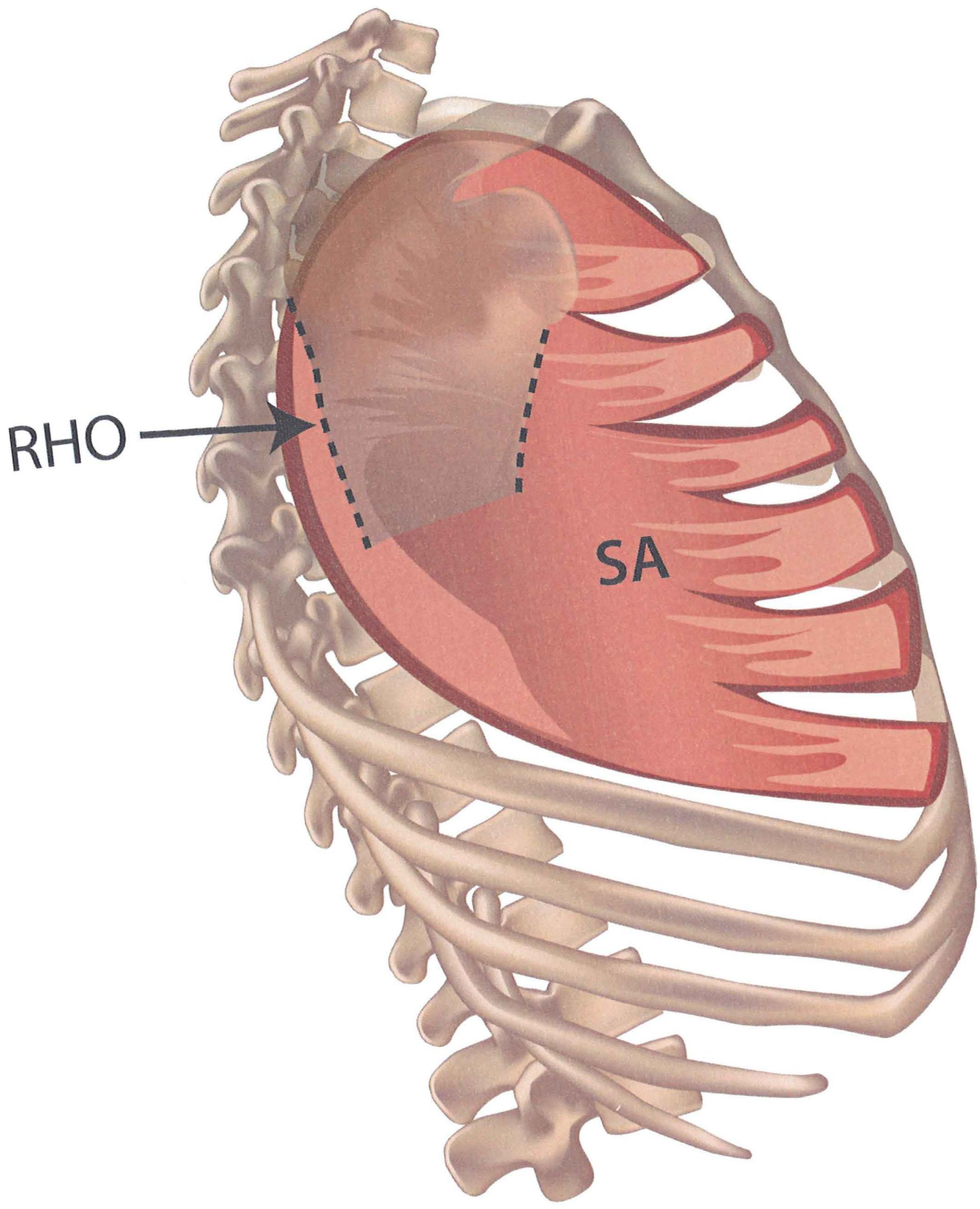

figure2b) 


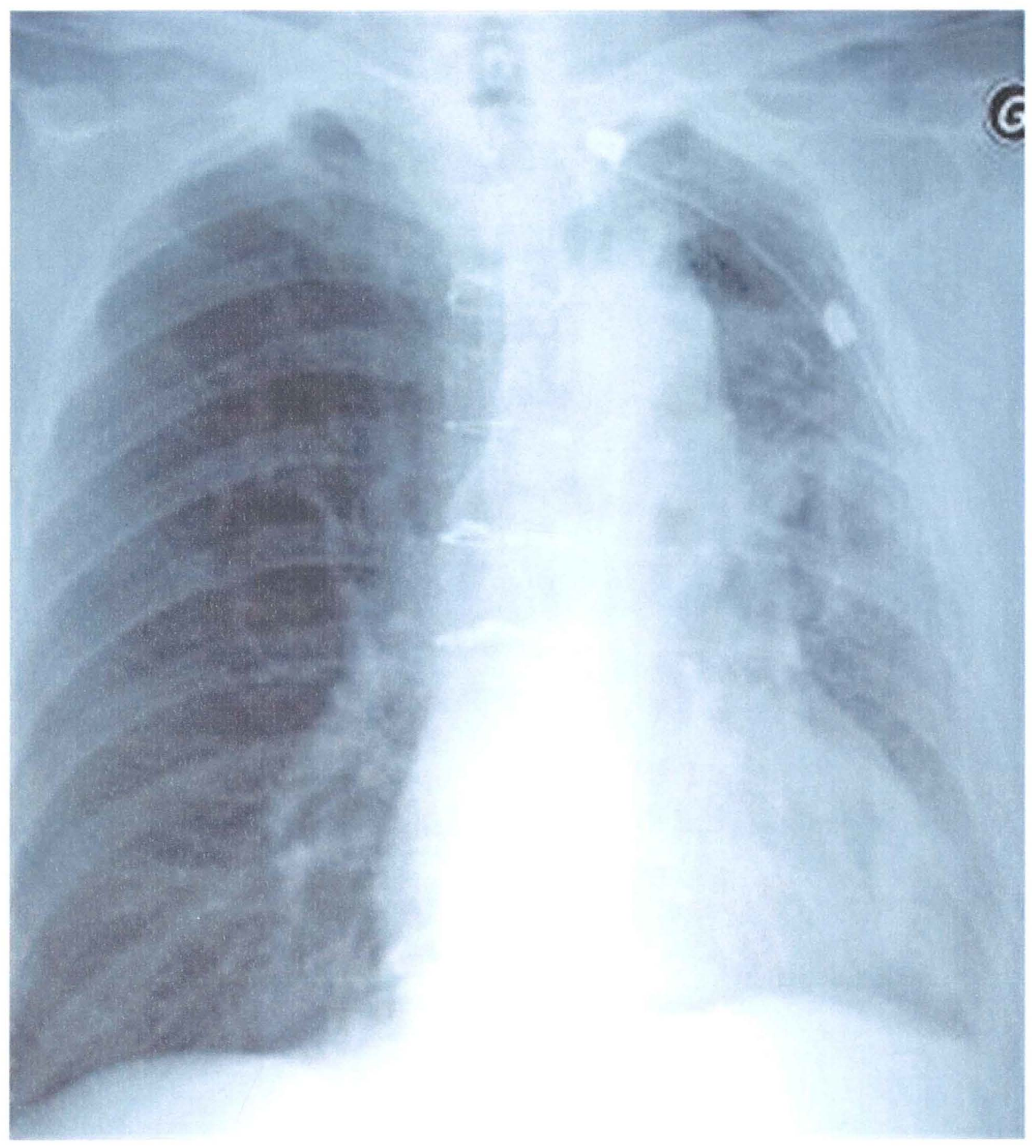

figure 3a) 


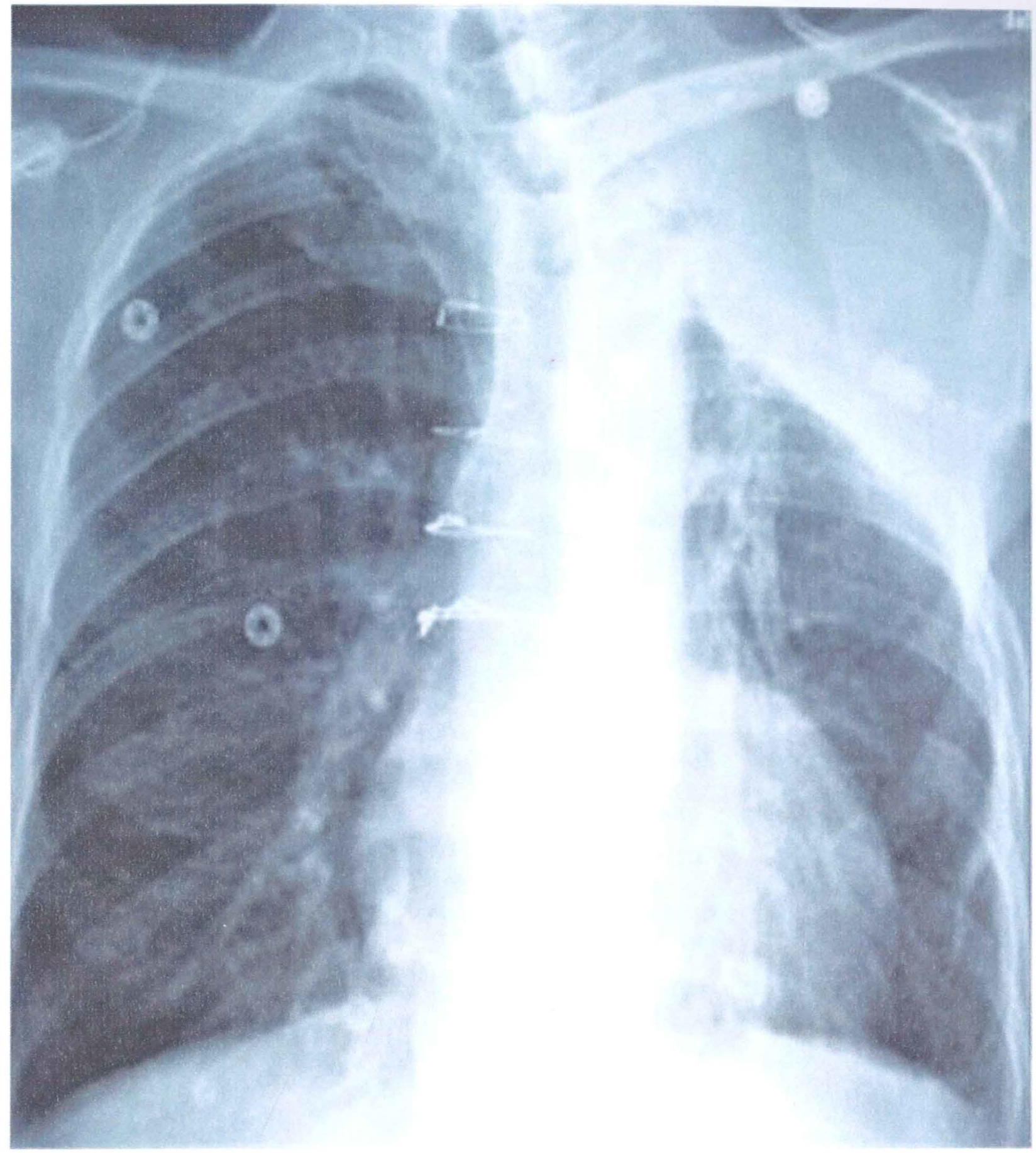

figure3b) 


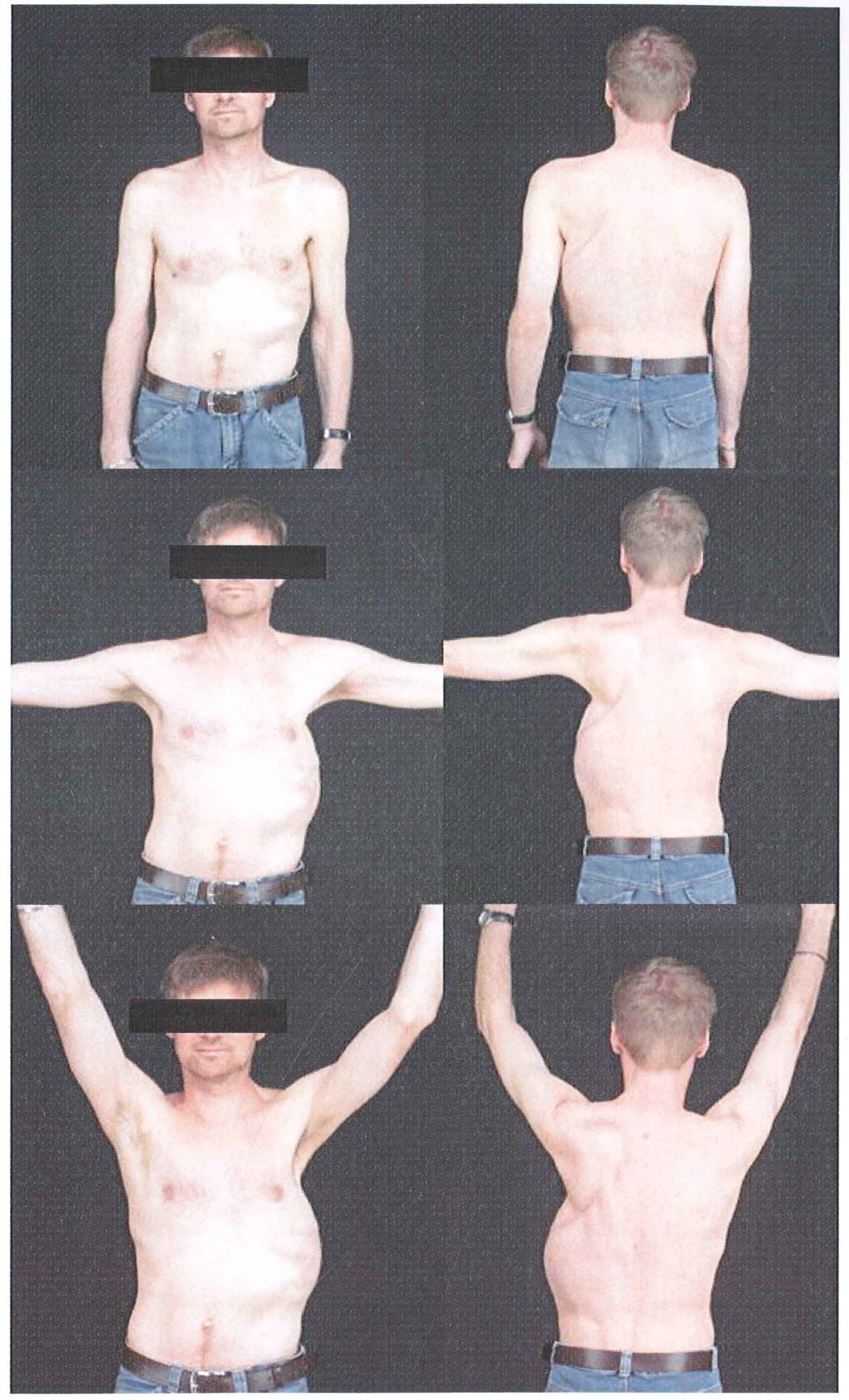

figure4 


\section{References}

1. Misthos P, Kokotsakis J, Konstantinou M, Skottis I, Lioulias A. Postoperative residual pleural spaces: characteristics and natural history. Asian Cardiovasc Thorac Ann 2007;15:54-58.

2. Massera F, Robustellini M, Della Pona C, Rossi G, Rizzi A, Rocco G. Open window thoracostomy for pleural empyema complicating partial lung resection. Annals Thorac Surg 2009;87:869-873.

3. A. Schmidt WM, H.B. Ris. Der residuelle postoperative pneumothorax: harmloser radiologischer befund oder komplikationstr!achtige diagnose? Schweiz Med Wochenschr 1995:1391-1395.

4. Gharagozloo F, Margolis M, Facktor M, Tempesta B, Najam F. Postpneumonectomy and postlobectomy empyema. Thoracic Surg Clinics 2006;16:215-222.

5. Keagy BA, Lores ME, Starek PJ, Murray GF, Lucas CL, Wilcox BR. Elective pulmonary lobectomy: factors associated with morbidity and operative mortality. Ann Thorac Surg 1985;40:349-352.

6. Deschamps C, Allen MS, Trastek VF, Pairolero PC. Empyema following pulmonary resection. Chest Surg Clin N Am 1994;4:583-592.

7. Cooper WA, Miller JI, Jr. Management of bronchopleural fistula after lobectomy. Semin Thorac Cardiovasc Surg 2001;13:8-12.

8. Lardinois D, Gock M, Pezzetta E, et al. Delayed referral and gram-negative organisms increase the conversion thoracotomy rate in patients undergoing video-assisted thoracoscopic surgery for empyema. Ann Thorac Surg 2005;79:1851-1856.

9. Molnar TF. Current surgical treatment of thoracic empyema in adults. Eur J Cardiothorac Surg 2007;32:422-430.

10. Deslauriers J, Jacques LF, Gregoire J. Role of Eloesser flap and thoracoplasty in the third millennium. Chest Surg Clin N Am 2002;12:605-623.

11. Saadi A, Perentes JY, Gonzalez M, et al. Vacuum-assisted closure device: a useful tool in the management of severe intrathoracic infections. Ann Thorac Surg 2011;91:1582-1589.

12. Okumura Y, Takeda S, Asada H, et al. Surgical results for chronic empyema using omental pedicled flap: long-term follow-up study. Ann Thorac Surg 2005;79:1857-1861.

13. Botianu PV, Dobrica AC, Butiurca A, Botianu AM. Complex space-filling procedures for intrathoracic infections - personal experience with 76 consecutive cases. Eur J Cardiothorac Surg 2010;37:478-481. 
14. Widmer MK, Krueger T, Lardinois D, Banic A, Ris HB. A comparative evaluation of intrathoracic latissimus dorsi and serratus anterior muscle transposition. Eur J Cardiothorac Surg 2000;18:435-439.

15. Regnard JF, Alifano M, Puyo P, Fares E, Magdeleinat P, Levasseur P. Open window thoracostomy followed by intrathoracic flap transposition in the treatment of empyema complicating pulmonary resection. J Thorac Cardiovasc Surg 2000;120:270-275.

16. Hopkins RA, Ungerleider RM, Staub EW, Young WG, Jr. The modern use of thoracoplasty. Ann Thorac Surg 1985;40:181-187.

17. Icard P, Le Rochais JP, Rabut B, Cazaban S, Martel B, Evrard C. Andrews thoracoplasty as a treatment of post-pneumonectomy empyema: experience in 23 cases. Ann Thorac Surg 1999;68:1159-1163; discussion 1164 .

18. Horrigan TP, Snow NJ. Thoracoplasty: current application to the infected pleural space. Ann Thorac Surg 1990;50:695-699.

19. Peppas G, Molnar TF, Jeyasingham K, Kirk AB. Thoracoplasty in the context of current surgical practice. Ann Thorac Surg 1993;56:903-909.

20. Stefani A, Jouni R, Alifano M, et al. Thoracoplasty in the current practice of thoracic surgery: a singleinstitution 10-year experience. Ann Thorac Surg 2011;91:263-268.

21. Garcia-Yuste M, Ramos G, Duque JL, et al. Open-window thoracostomy and thoracomyoplasty to manage chronic pleural empyema. Ann Thorac Surg 1998;65:818-822.

22. Krassas A, Grima R, Bagan P, et al. Current indications and results for thoracoplasty and intrathoracic muscle transposition. Eur J Cardiothorac Surg 2010;37:1215-1220.

23. Meyer AJ, Krueger T, Lepori D, et al. Closure of large intrathoracic airway defects using extrathoracic muscle flaps. Ann Thorac Surg 2004;77:397-404; discussion 405.

24. Ris HB, Krueger T, Cheng C, Pasche P, Monnier P, Magnusson L. Tracheo-carinal reconstructions using extrathoracic muscle flaps. Eur J Cardiothorac Surg 2008;33:276-283.

25. Jadczuk E. Posptneumonectomy empyema. Eur J Cardiothorac Surg 1998;14:123-126. 